\title{
Recorregut de recerca geològica i mineralògica per les comarques de la terra alta i del Matarranya: des d'Horta de Sant Joan i Arnes a Vall-de-Roures i a Beseit; i des de Beseit al Parrissal i a Formenta
}

Josep Maria Mata-Perelló

Andrés Pocoví Juan

Joaquim Sanz Balagué

Jaume Vilaltella

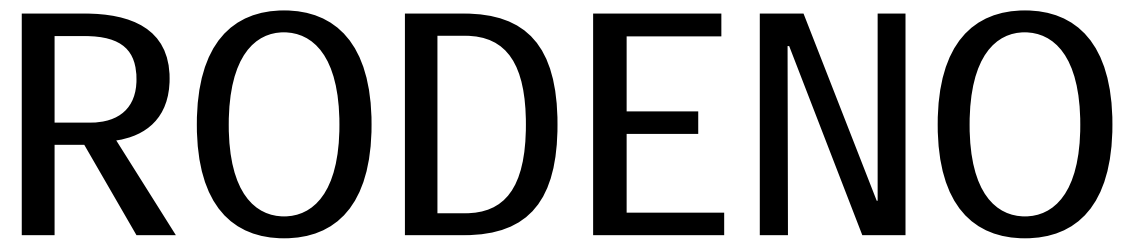

\section{REVISTA DE GEOLOGÍA ARAGONESA}

\section{ก. 3}

SEPTIEMBRE 2015 


\title{
RECORREGUT DE RECERCA GEOLÒGICA I MINERALÒGICA PER LES COMARQUES DE LA TERRA ALTA I DEL MATARRANYA: DES D'HORTA DE SANT JOAN I ARNES A VALL-DE-ROURES I A BESEIT; I DES DE BESEIT AL PARRISSAL I A FORMENTA
}

\author{
Josep Maria Mata-Perelló \\ Museu de geologia Valentí Masachs, Escola Politècnica Superior d'Enginyeria de Manresa \\ (EPSEM), Universitat Politècnica de Catalunya · BarcelonaTech (UPC), 08272 Manresa, Spain
}

\section{Andrés Pocovi Juan}

Universidad de Zaragoza, Departamento de Ciencias de la Tierra ( DCT- UZ)

\section{Joaquim Sanz Balagué}

Departament d'Enginyeria Minera i Recursos Naturals (EMRN), Escola Politècnica Superior d'Enginyeria de Manresa (EPSEM), Universitat Politècnica de Catalunya - BarcelonaTech (UPC), 08272 Manresa, Spain

Jaume Vilaltella Farràs.

Sociedad Española para la Defensa del Patrimonio Geológico y Minero (SEDPGYM)

Palabras clave: patrimonio minero; patrimonio geológico

\section{Resumen}

Recorregut realitzat el 16 de novembre de 2013 1. En aquesta ocasió, el recorregut del present itinerari discorrerà per una zona en la qual conflueixen tres unitats geològiques netament diferenciades: la Depressió Geològica de I'Ebre, la Serralada Prelitoral Catalana (del Sistema Mediterrani), i la Serralada Ibèrica.

Així, en els primers trams del recorregut, entre Horta de Sant Joan, Arnes i Vall-de-roures el recorregut transitarà per la primera unitat esmentada, entre afloraments de materials cenozoics. Més endavant, cap els voltants de Beseit ho farà per la segona unitat, a la denominada Zona d'Enllaç, prop ja del Sistema Ibèric.

Per d'altra banda, el recorregut de l'itinerari, es repartirà entre dues comarques, de la Regió de Tortosa. Així, el primer tram del recorregut, pels voltants d’horta de Sant Joan i Arnes, es transitarà per la comarca de la Terra Alta. La resta del recorregut, entre Vall-de-roures i Beseit s'efectuarà per la comarca del Matarranya.

1 Aquest recorregut constitueix una modificació de l'itinerari: RECORREGUT DE RECERCA GEOLÒGICA I MINERALÒGICA PER LES COMARQUES DE LA TERRA ALTA I DEL MATARRANYA: DES D’HORTA DE SANT JOAN I ARNES A VALL-DE-ROURES I A BESEIT, realitzat el 29a D’OCTUBRE DEL 2011

Rodenol.2015 n.3 | Recorregut de recerca geològica i mineralògica per les comarques de la terra alta i del Matarranya: des d'Horta de Sant Joan i Arnes a Vall-de-Roures i a Beseit; i des de Beseit al Parrissal i a 


\section{ADVERTIMENTS PREVIS}

Com en altres recorreguts de RECERCA GEOLÒGICA I MINERALÒGICA ..., si es disposa del temps suficient, poden efectuar-se passant per totes les parades i filloles. En cas contrari, recomanem prescindir de les anomenades PARADES - CONDICIONALS.

També recomanem de cercar la informació més adient, sobre els trams a recórrer mitjançant camins de terra, o de pista. Precisament, en aquest itinerari, hi ha alguns trajectes d'aproximació cap a les mines, que haurem de fer per camins de terra en irregular estat de conservació. Aquest és el cas de l'aproximació cap el Parrissal i cap a Formenta, des de Beseit.

Per d'altra banda, recomanem tenir una cura extrema de la NATURA, evitant qualsevol forma d'agressió sobre ella, o de fer-n'hi un mal ús del que en ofereix la nostra mare Terra.

\section{OBJECTIUS FONAMENTALS D’AQUEST ITINERARI}

Els objectius fonamentals que es pretenen aconseguir en aquest itinerari, es poden concretar en els següents aspectes generals:

1.- Observació i descripció dels materials terciaris (de l'Eocè i de l'Oligocè) de la Depressió Geològica de l'Ebre, que pertanyen majoritàriament al complex al·luvial de Gandesa - Horta de Sant Joan, que inclou, entre altres a la Formació Montsant i a la Formació Flix. Aquests materials, els anirem trobant a diferents indrets del recorregut de l'itinerari. Primer pels voltants d'Horta de Sant Joan i Arnes, tot anant cap a Vall-de roures; i més endavant entre aquesta població i Beseit. Cal dir que bona part d'aquesta zona, s'inclou dintre del denominat Avant-país, situat al contacte entre la Depressió Geològica de l’Ebre i la Serralada Ibèrica.

2.- Observació i descripció dels materials mesozoics (del Triàsic, del Juràssic i del Cretàcic) i dels cenozoics (de l'Eocè i de l'Oligocè), que constitueixen la Serralada Prelitoral Catalana,. Aquests materials els trobarem a diferents indrets del recorregut de l'itinerari, especialment entre Vall-de-roures i Beseit.

3.- Observació de les estructures locals d'aquestes unitats geològiques acabades d'esmentar, que trobarem al llarg del recorregut de l'itinerari, i de les relacions existents entre elles. Així:

3A) de l'estructura de la Depressió Geològica de l'Ebre, que veurem als primers trams del recorregut.

3B) de l'estructura de Branca Externa de la Serralada Prelitoral Catalana (integrant del Sistema Mediterrani), que trobarem a diferents trams del recorregut. En molts indrets, aquests es troben prop de la seva Zona d'Enllaç amb el Sistema Ibèric.

Rodenol.2015 n.3 | Recorregut de recerca geològica i mineralògica per les comarques de la terra alta i del 
3C) de les relacions existents entre les unitats i sotsunitats geològiques acabades d'esmentar.

4.- Observació i reconeixement de diferents mineralitzacions situades a diferents indrets del recorregut de l'itinerari, (però sempre dintre de les dues branques de la Serralada Prelitoral Catalana), com són les següents:

4A) les formacions i explotacions lutítiques, situades fonamentalment a Beseit, dintre de la comarca del Matarranya, dintre de l’Albià (Cretàcic Inferior).

4B) i les mineralitzacions ferruginoses associades a lignits mesozoics, situades al terme de la Beseit (Matarranya).

5.- Observació de les antigues explotacions mineres relacionades amb les mineralitzacions anteriors. Al respecte, cal dir que totes elles es troben actualment aturades.

6.- Observació i anàlisi dels impactes produïts sobre el Medi Natural (i sobre el Medi Ambient), tant per les explotacions mineres anteriors, com per altres activitats humanes.

7.- Observació dels diferents indrets relacionats amb el Patrimoni Geològic i Miner, que trobarem al llarg del recorregut.

\section{ANTECEDENTS BIBLIOGRÀFICS}

Pel que fa al recorregut del present itinerari, existeixen alguns antecedents molt propers, obra del mateix autor del present itinerari. Es tracta de MATA-PERELLÓ (1996b, 1997, 2000a, 2000b, 2001a i 2001b). Un altre antecedent parcial, obra del mateix autor, es troba a MATA-PERELLÓ (1989), i correspon a un altre itinerari. Tot i així, cal fer esment del nostre treball (MATA - PERELLÓ, 2011), del qual aquest és una actualització i ampliació.

Pel que fa a la descripció de les mineralitzacions d'aquesta comarca, farem esment d'un altre treball del mateix autor, de MATA-PERELLÓ (1991), relatiu a les mineralitzacions catalanes en general. Uns altres antecedents, cal situar-los en MATAPERELLÓ (1995a, 1995b, 2005a i 2005b), relatius als inventaris mineralògics de les comarques de la Terra Alta i del Matarranya.

I, finalment, pel que fa a l'estructura geològica de la zona per la qual discorre l'itinerari, farem esment dels treballs de GUIMERÀ et altri (1982) i de RIBA et altri (1976). També, i dintre d'aquest apartat, també farem esment de diversos treballs de l'IGME (1972). Tots ells són relatius a diversos fulls geològics corresponents als indrets per on passarà el recorregut de l'itinerari.

Rodenol.2015 n.3 | Recorregut de recerca geològica i mineralògica per les comarques de la terra alta i del 
Tots aquests treballs referenciats, i d'altres, figuren esmentats per ordre alfabètic a l'apartat dedicat a la BIBLIOGRAFIA.

\section{RECORREGUT DE L'ITINERARI}

El recorregut de l'itinerari començarà dintre de la comarca de la Terra Alta, concretament a la població d'Horta de Sant Joan, per on s'efectuarà la primera aturada. Tot seguit, el recorregut es dirigirà cap al poble veí d'Arnes, des d'on s'anirà cap a Vallde-roures, passant en aquest tram del recorregut de la comarca de la Terra Alta a la comarca del Matarranya.

Així, s'haurà arribat a l'esmentat Vall-de-roures, la capital comarcal. Des d'aquest darrer poble, el recorregut es dirigirà cap a la població de Beseit, per on es faran dues noves parades, totes dues abans d'arribar-hi. Després, el recorregut es dirigirà cap al Parrissal i cap a Formenta, per on es realitzaran diverses aturades, abans de finalitzar el recorregut al terme de Beseit.

\section{DESCRIPCIÓ DE L'ITINERARI}

Com de costum, estructurarem el recorregut de l'itinerari en una sèrie de PARADES, que tot seguit anirem veient. En cada una d'aquestes aturades farem un breu comentari (geològic o mineralògic, segons s'escaigui). Cada una d'aquestes parades tindrà un número, i un topònim representatiu. Per d'altra banda, s'indicarà el nom del poble més proper, el municipi al qual pertany l'indret, i la comarca on es troba situat. Per d'altra banda, també indicarem en cada cas, i entre parèntesi, el full topogràfic on es troba l'aturada.

Finalment, cal dir que el recorregut de l'itinerari s'inclourà dintre dels següents fulls, del "Mapa Topográfico Nacional", realitzats a l'escala 1:50.000 per l'"Instituto Geográfico y Catastral": 496 (dit d'Horta de Sant Joan), 520 (dit de Pena-roja de Tastavins) i 521 (dit de Beseit.).

Així doncs, la relació de parades ordenades, que composen aquest itinerari geològic i mineralògic, és el següent:

PARADA 1. SORTIDA D'HORTA DE SANT JOAN, CAP A VALL-DEROURES. CASERNA DELS BOMBERS, (terme municipal d'Horta de Sant Joan, comarca de la Terra Alta). (Full 496). 
El recorregut ens caldrà iniciar-lo al poble d'Horta de Sant Joan, dintre de la comarca de la Terra Alta. Des del bel mig del poble, ens caldrà anar cap a la carretera que enllaça amb la que comunica Prat de Compte amb Vall-de-roures (la T-334 i la T-330, respectivament). A poc menys d'un Km, farem una aturada, ben prop de la caserna dels bombers voluntaris.

En aquest recorregut, des d'Horta de Sant Joan, s'han continuat tallant els materials terciaris, que tornen a ésser majoritàriament de la Formació Flix. Aquests són els que apareixen a l'indret de l'aturada.

Des d'aquest indret, mirant cap el Nord, es poden veure els relleus de Sant Salvador. I especialment, es pot veure la magnífica discordança progressiva, descrita pels terrenys detrítics del cenozoics. FOTOGRAFÍA 1, situada a la pàgina següent.

PARADA 2. BARRANC DEL SALT, ROQUES DE BENET, (terme municipal d’Horta de Sant Joan, comarca de la Terra Alta). (Full 496).

Després de realitzar la parada anterior ens caldrà continuar per la carretera local T334, amb la intenció d'arribar a la cruïlla amb la T-330. En trobar-la, caldrà anar en sentit occidental, durant uns 100 metres, fins trobar la cruilla d'on eix la carretereta que se'n va cap a les immediacions de les Roques de Benet. En caldrà agafar-la, per tal de recórrer uns $2 \mathrm{Km}$ i fer una nova aturada, davant d'un mirador, on hi ha uns plafons. Així, des de la parada anterior, haurem recorregut uns $3 \mathrm{Km}$ més.

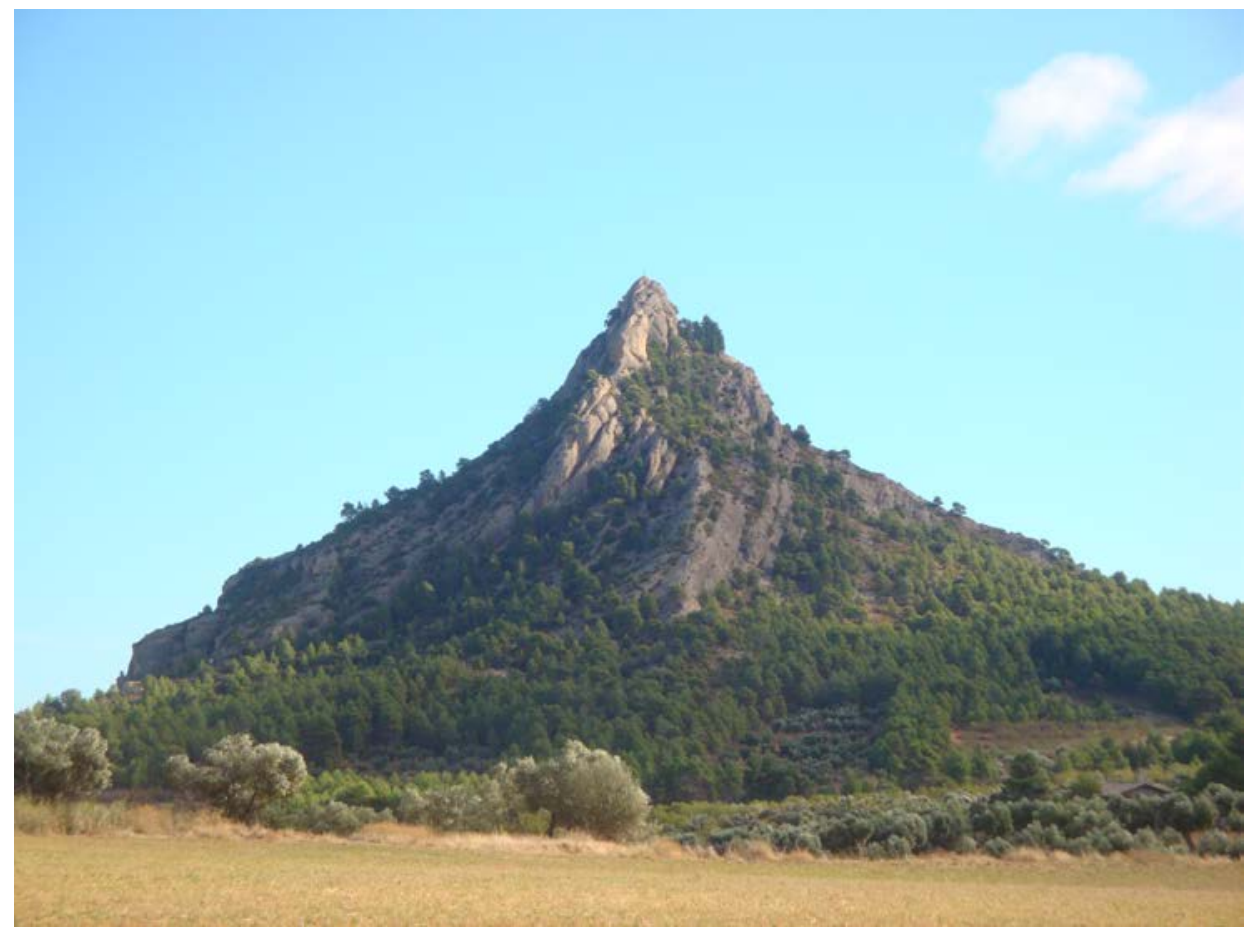

Rodenol.2015 n.3 | Recorregut de recerca geològica i mineralògica per les comarques de la terra alta i del 
FOTOGRAFIA 1 (PARADA 1)

Muntanya de Santa Bárbara. Sant Salvador d’Horta

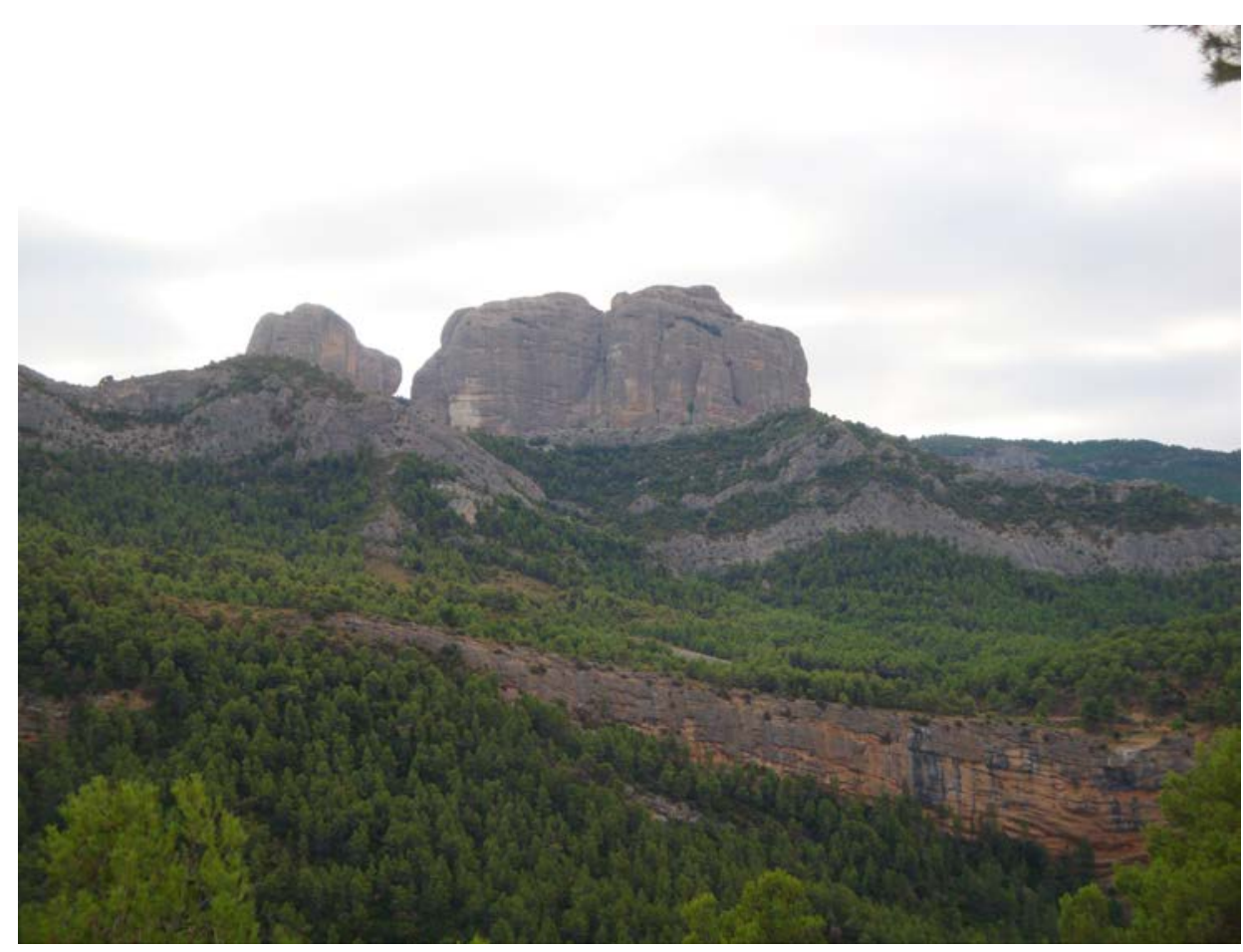

FOTOGRAFIA 2 (PARADA 2)

Un aspecte de les Roques de Benet

En aquest recorregut, des de la parada anterior, s'han continuat tallant els materials terciaris, que tornen a ésser majoritàriament de la Formació Flix. Aquests materials els hem anat trobant fins a l'indret de l'aturada.

Des d'aquest lloc es pot veure l'impressionant relleu de les Roques de Benet, integrant de la Zona d'Enllaç de la Serralada Prelitoral Catalana amb el Sistema Ibèric. Els materials que constitueixen aquesta serralada són eminentment calcaris, i pertanyen al Juràssic i al Cretàcic. Per sobre d'aquests materials mesozoics acabats d'esmentar, es troben uns interessants afloraments dels nivells detrítics dels trams superiors de la Formació Montsant (que com ja s'ha dit, aquí forma part del Complex al·luvial de Gandesa-Horta de Sant Joan). FOTOGRAFIA 2 (situada a la pàgina anterior).

Aquests materials són lleugerament posttectònics, tot i que es troben lleugerament deformats per des darreres convulsions.

PARADA 3 - CONDICIONAL. PONT SOBRE EL RIU ALGARS, (terme municipal d'Arnes, comarca de la Terra Alta). (Full 496).

Rodenol.2015 n.3 | Recorregut de recerca geològica i mineralògica per les comarques de la terra alta i del 
Des de la parada anterior, cal anar cap al poble d'Arnes, sobrepassant-lo. Després caldrà arribar fins al riu Algars, per on farem la darrera aturada del recorregut, si s'escau. Així, haurem recorregut uns $8 \mathrm{Km}$ més, per tal d'arribar fins on ara som.

En aquest recorregut hem anat circulant entre els materials cenozoics de la Depressió Geològica de l'Ebre, on ara som. Tot i això som molt propers a la Serralada Prelitoral Catalana. En bona part, aquests materials, de tonalitats ocres, pertanyen al Complex Al-luvial de Gandesa - Horta de Sant Joan.

En aquest indret farem la darrera aturada, a la vora del riu Algars, el qual procedeix de la Serralada. Més lluny, prop de Nonasp, aquest riu fa el seu aiguabarreig amb el Matarranya, arribant tots dos a l'Ebre, prop de Faió.

\section{PARADA 4. BARRANC DE MATALLOPS, (terme municipal de Vall-de- roures, comarca del Matarranya). (Full 496).}

Des de la parada anterior, es deixa la comarca de la Terra Alta, i es penetra a la del Matarranya. En aquest moment, la carretera varia de denominació. i passa a ésser la carretera autonòmica aragonesa A-231. Més endavant s'arriba quasi a la capital comarcal, a Vall-de-roures. Poc abans d'arribar-hi, es troba el trencall que per l'esquerra condueix cap a Beseit, cap a on cal anar-hi. A 1'5 Km del trencall, cal fer la parada. Així, des de la parada anterior, s' haurà fet un llarg recorregut, de prop de $8 \mathrm{Km}$.

En la major part del recorregut, hem anat circulant per entre els materials cenozoics de la Depressió Geològica de l'Ebre. Sovint, hem trobat aquests materials recoberts per terrenys detrítics quaternaris. Així, s'han anat tallant els nivells sorrencs i lutítics (calcolutítics), de la Formació Flix. Aquests materials els hem continuat trobant fins prop de Vall-de-roures. Poc després de l'inici del trencall, s'han tornat a trobar el nivells detrítics de la Formació Montsant. Uns i altres, que pertanyen a la Depressió Geològica de l'Ebre, formen part del Complex al·luvial de Gandesa-Horta de Sant Joan.

Tot i així, a l'indret de l'aturada s'ha fet clarament palès el contacte d'aquests materials, amb els terrenys eminentment carbonatats del Juràssic i del Cretàcic, de la Zona d'Enllaç del Sistema Ibèric - Serralada Prelitoral Catalana, que en aquest indret formen part de la làmina d'encavalcament de la Pena. Aquest contacte es realitza per encavalcament, dels materials mesozoics de la Zona d'Enllaç sobre els cenozoics de la depressió.

PARADA 5. RELLEUS D’ENQUEROL, (terme municipal de Vall-deroures, comarca del Matarranya). (Full 496). 
Després de fer la parada anterior, cal fer un petit recorregut de 0’5 Km, per la carretera que es dirigeix cap a Beseit. En arribar al peu d'Enquerol, caldrà fer una nova aturada, dintre del recorregut d'aquest itinerari.

Després de fer l'aturada anterior. hem començat a tallar els afloraments dels materials carbonatats mesozoics (del Juràssic i del Cretàcic) de la làmina d'encavalcament de la Pena, integrada a la Zona d'Enllaç de la Branca Externa de la Serralada Prelitoral Catalana amb el Sistema Ibèric.

Aquests materials es troben intensament replegats, com a conseqüència d'aquest encavalcament. Així és com els podem veure a l'indret de la present aturada, per sobre del riu Matarranya.

Cal destacar, per d'altra banda, que en aquest indret es van utilitzar les aigües del riu, per tal de moure una sèrie d'indústries situades a la seva bora, les qual es troben ara totalment inactives.

\section{PARADA 6. PEDRERA I MINA D'ARGILA "MARIA DOLORS", (terme municipal de Beseit, comarca del Matarranya). (Full 521).}

Des de la parada anterior, cal continuar cap al poble de Beseit. Molt poc abans d'arribar-hi, cal agafar un trencall per la dreta, que en $1 \mathrm{Km}$ arriba a les explotacions argiloses de la Mina Dolors, on efectuarem la present parada, després d'un recorregut d'uns $3 \mathrm{Km}$, des de la parada anterior.

En aquest breu recorregut, des de la parada anterior, s'han anat tallant els materials mesozoics, del Juràssic i del Cretàcic, que constitueixen part de la làmina d'encavalcament de la Pena. En aquest indret, es troba una explotació dels nivells lutítics cretàcics, que pertanyen a l'Albià, i més concretament a la Formació Utrillas.

Entre les argiles, el mineral més abundant és la CAOLINITA. Per d'altra banda, hi ha una notable presència dels òxids de ferro, especialment de l'HEMATITES (normalment terròs) i de la GOETHITA (la qual es presenta terrosa, en forma de LIMONITA).

Darrerament, aquests nivells argilosos han estat explotats per mineria a "cel obert" (o a "tall obert", com es diu a la zona). Tot i així, les primeres explotacions es van efectuar per mineria soterrània. FOTOGRAFIA 3- 


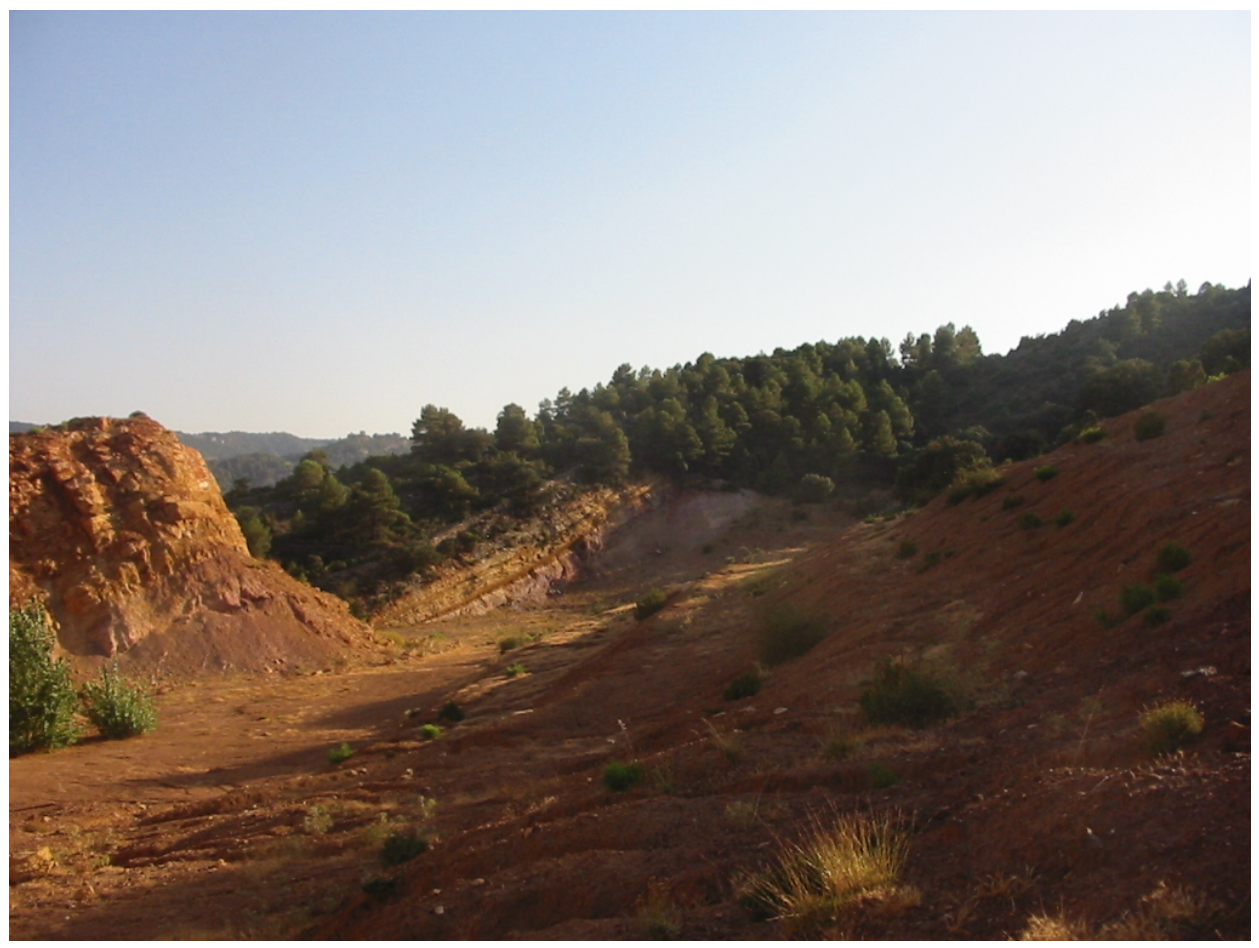

FOTOGRAFIA 3 (PARADA 6)

Un aspecte de les antigues explotacions argiloses de la Mina Dolores

PARADA 7. COVA DE L'AIRE, (terme municipal de Beseit, comarca del Matarranya). (Full 521).

Des de la parada anterior, cal anar cap a Beseit. Després, caldrà ascendir pel Riu Matarranya, fins arribar a la Cova de l'Aire. Aquí es farà una nova aturada, a uns $5 \mathrm{Km}$ de l'anterior.

En aquest recorregut, en un principi s'han tornat a tallar els nivells detrítics de la Formació Montsant, just després de sobrepassar la làmina d'encavalcament de l'embassament de la Pena. És a dir, continuem dintre de la Depressió Geològica de l'Ebre; tot i que ens trobem situats dintre de la Zona de l'Avant-país plegat.

Més endavant s'han tornat a trobar afloraments dels materials mesozoics del Juràssic i del Cretàcic, els quals encavalquen als anteriors, com es pot veure en aquest indret on som ara. Efectivament, aquests materials mesozoics, es troben força replegats. FOTOGRAFIA 4.

Per d'altra banda, cal destacar la presència d'uns interessants nivells travertinics, desenvolupats a partir de la circulació d'aigües soterrànies per entre els nivells carbonatats

Rodenol.2015 n.3 | Recorregut de recerca geològica i mineralògica per les comarques de la terra alta i del 
mesozoics. Efectivament, aquests nivells es troben situats entre les calcàries, i prop del contacte d'aquestes amb els materials terciaris anteriorment esmentats.

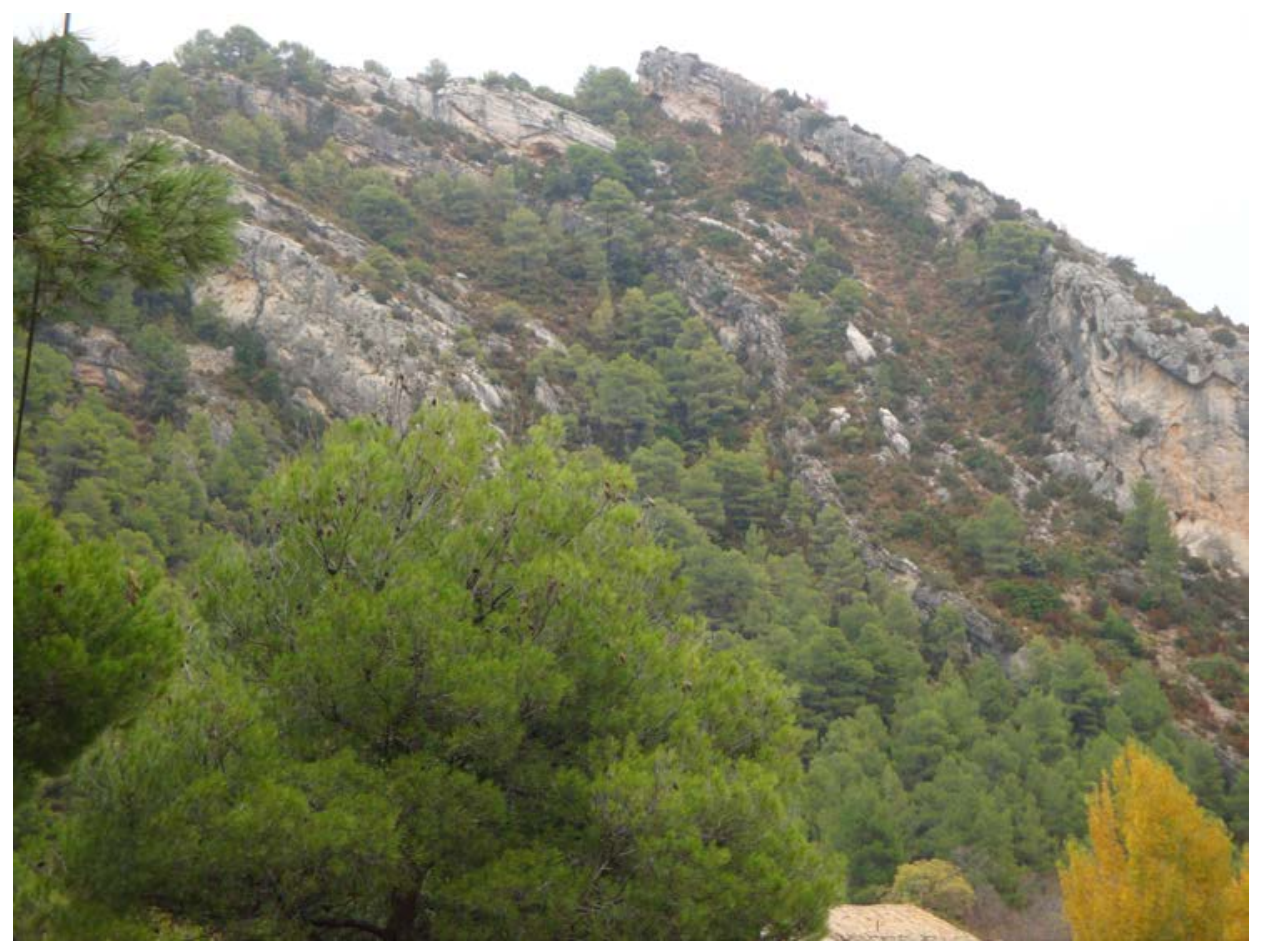

FOTOGRAFIA 4 (PARADA 7)

Materials mesozoics carbonatats cretàcics, plegat a la Cova de l'Aire. Beseit

PARADA 8 - CONDICIONAL. MINA MARUJA DE LIGNITS, EL PARRISSAL, (terme de Beseit, comarca del Matarranya). (Full 521).

Des de la parada anterior, cal continuar ascendint pel Riu Matarranya, fins arribar al Parrissal, en un recorregut d'uns 3-4Km per una pista que no es troba en gaire bones condicions. En passar aquest lloc, s'arriba a les immediacions de la Mina Maruja, la qual es troba situada a la dreta del riu, en sentit ascendent. Per arribar-hi cal agafar un corriol, arribant-hi en una mitja hora.

En aquest recorregut, des de la parada anterior, s'han tornat a trobar els nivells terciaris de la Formació Montsant, després de sobrepassar la làmina de l'encavalcament de l'embassament de la Pena. Després, i ben seguit, des de Beseit, s'han tornat a trobar els nivells mesozoics del Juràssic i del Cretàcic, fins arribar a l'indret on ara ens trobem.

Aquests materials formen part d'un conjunt d'encavalcaments, de direcció (en aquests indrets) E-W, i que formen part de l'anomenat "sistema d'encavalcaments 
imbricats, del cinturó Portalrubio - Vandellòs", (d'acord amb els treballs de GUIMERA, et altrii, 1992).

En aquest indret, hi ha un aflorament dels materials de l'Albià (i més concretament de la seva Formació Utrillas). A l'aflorament es troben uns nivells terrígens, $i$ entre ells hi ha presència de lignits, els quals han estat explotats en diferents indrets, $i$ en diferents èpoques. Des de la mina, baixaven els carbons cap a una explanada on era carregat. Actualment sols es conserven algunes de les pilones per on baixaven els materials explotats a la mina. FOTOGRAFIA 5.

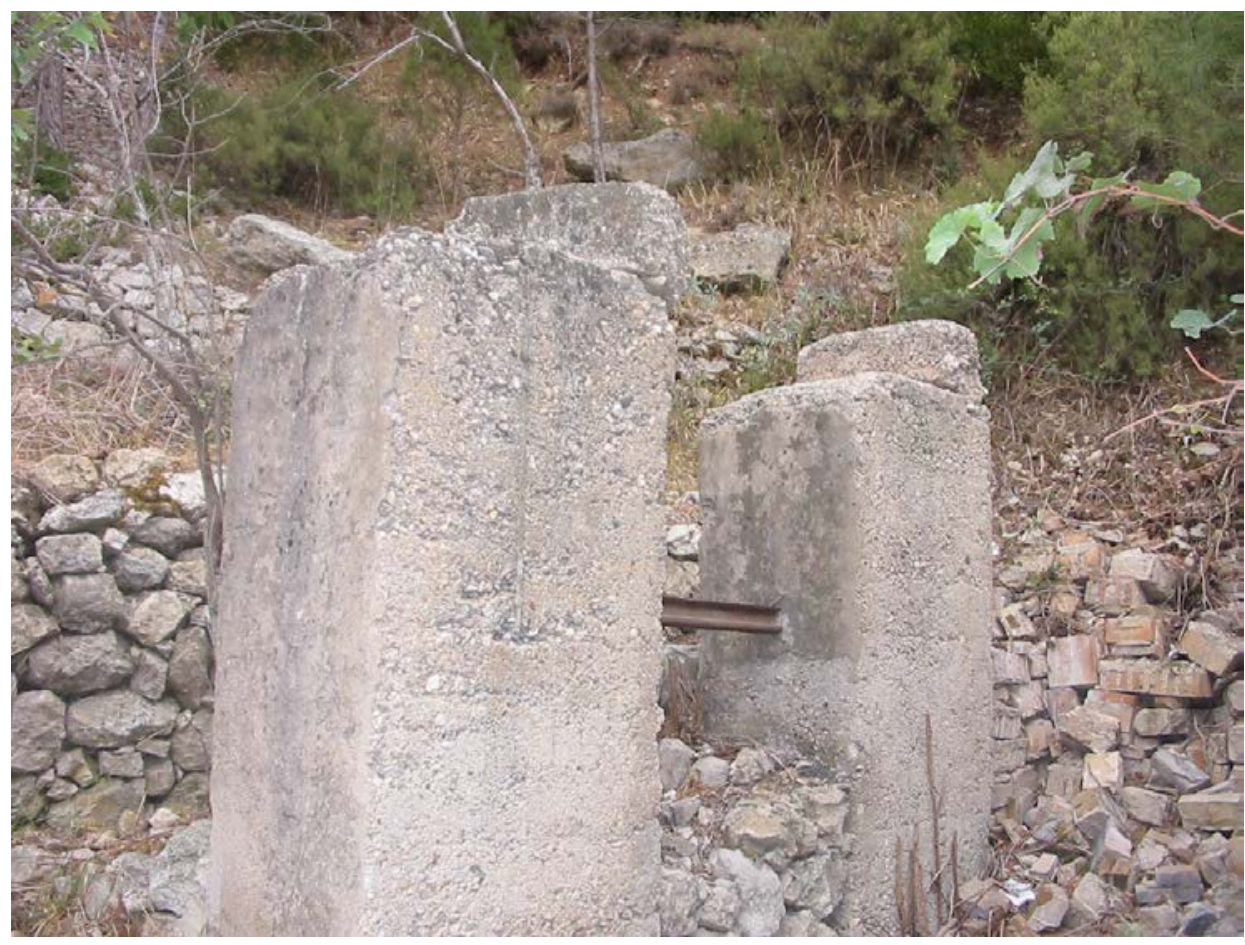

FOTOGRAFIA 5 (PARADA 8)

Restes de la part final del telefèric de la mina Maruja Beseit

Entre els lignits, hi ha presència de sulfurs de ferro, de caràcter primari. entre ells hi ha la PIRITA, així com la MARCASSITA. Igualment, hi ha indicis de la MELNIKOWITA, un mineral trimorf amb els dos anteriors. Tot i així, el primer és el més representatiu. Conjuntament amb els anteriors, també es troben altres minerals, tot formant part de la roca, com els tres següents: CALCITA, CAOLINITA (molt abundant) $i$ QUARS.

Per l'oxidació d'aquests sulfurs acabats d'esmentar, s'ha produït la formació de diversos minerals d'alteració, com de GOETHITA (la qual és sempre molt terrígena, apareixen en forma de la roca LIMONITA). També es troben altres minerals com: GUIX

Rodenol.2015 n.3 | Recorregut de recerca geològica i mineralògica per les comarques de la terra alta i del Matarranya: des d'Horta de Sant Joan i Arnes a Vall-de-Roures i a Beseit; i des de Beseit al Parrissal i a 
(originat al reaccionar l'àcid sulfúric, procedent de l'alteració dels sulfurs de ferro, amb la CALCITA), i la MELANTERITA.

Finalment, cal dir que a més a més de la Mina Maruja, existeixen algunes altres mines, dedicades a l'extracció dels lignits.

PARADA 9. ELS TRAVERTINS DEL PARRIZAR, (terme municipal de Beseit, comarca del Matarranya). (Full 521).

Des de la parada anterior, cal continuar ascendint el riu Matarranya, fins arribar a les immediacions del Parrissal. Poc abans d'arribar-hi, trobarem uns interessants travertins, per on efectuarem una nova aturada, a uns $3 \mathrm{Km}$ de la parada anterior.

Com als trams anteriors, aquest recorregut s'haurà efectuat per entre afloraments dels materials mesozoics (del Juràssic i del Cretàcic). Aquests terrenys, on ens trobem ara situats, formen part de la denominada Zona d'Enllaç entre la Serralada Prelitoral Catalana i el Sistema Ibèric.

En aquest lloc, hi ha un afloraments de travertins, situats prop del riu Matarranya, on ara ens trobem. Tanmateix, mirant al riu es poden veure processos de formació d'aquestes roques carbonatades. FOTOGRAFIA 6.

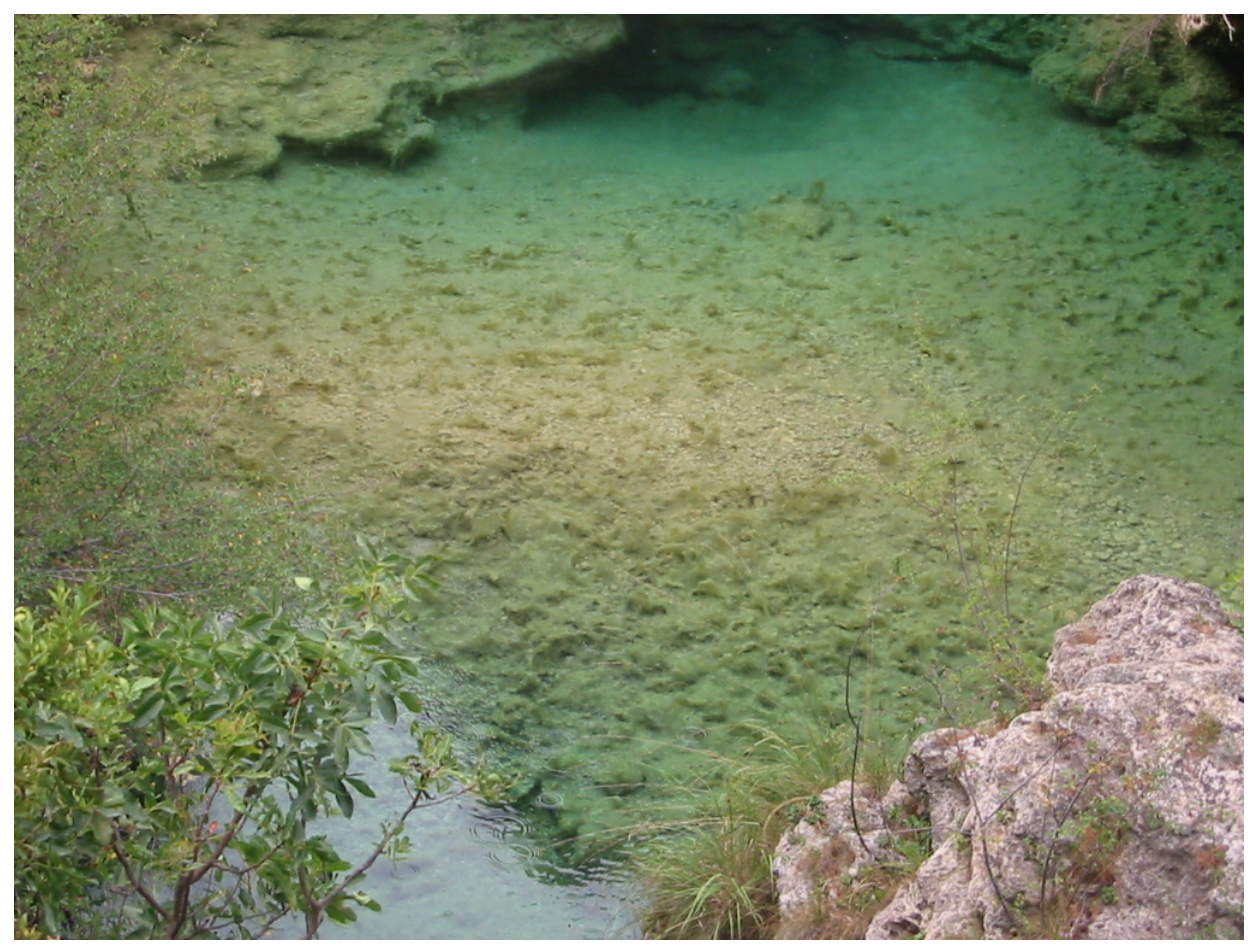

Rodenol.2015 n.3 | Recorregut de recerca geològica i mineralògica per les comarques de la terra alta i del 
FOTOGRAFIA 6 (PARADA 9)

Els travertins i la travertinització, prop del Parrissal

\section{PARADA 10. LES GÜBIES DEL PARRSSAL, (terme municipal de Beseit, comarca del Matarranya). (Full 521).}

Des de la parada anterior, cal continuar ascendint el riu Matarranya, fins arribar al Parrissal; en arribar-hi, efectuarem una nova aturada, a menys de1 Km de la parada anteriorment realitzada.

En aquest recorregut, hem continuat trobant afloraments dels materials mesozoics esmentats a les aturades anteriors. Aquests materials són els que afloren a l'indret de la present aturada. Així, en aquest recorregut entre els materials mesozoics, haurem travessat un túnel, en el qual es pot veure una interessant fractura que el travessa. FOTOGRAFIA 7.

En aquest indret de la present aturada hi ha un interessant encaixonament obert pel riu Matarranya en travessar aquests materials mesozoics. FOTOGRAIA 8.

Aquest indret constitueix un dels LIG (Lloc d'Interès Geològic de la Comarca del Matarranya i també del conjunt d'Aragó). Aquest encaixonaent dona lloc a les anomenades gúbies del riu Matarranya.

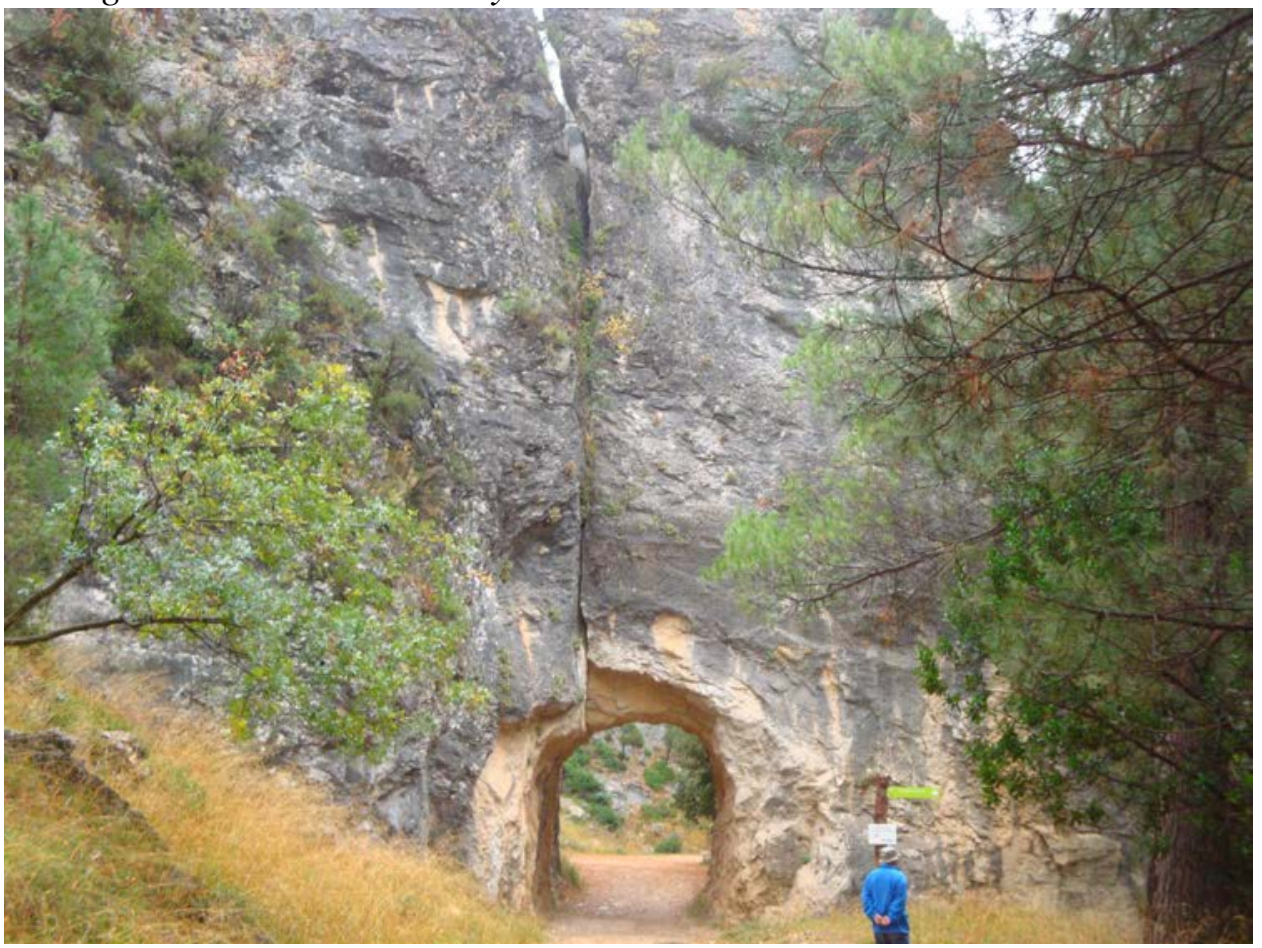

FOTOGRAFIA 7 (PARADA 10)

Un aspecte del túnel del Parrissal i de la fractura que el travessa. Beseit

Rodenol.2015 n.3 | Recorregut de recerca geològica i mineralògica per les comarques de la terra alta i del 


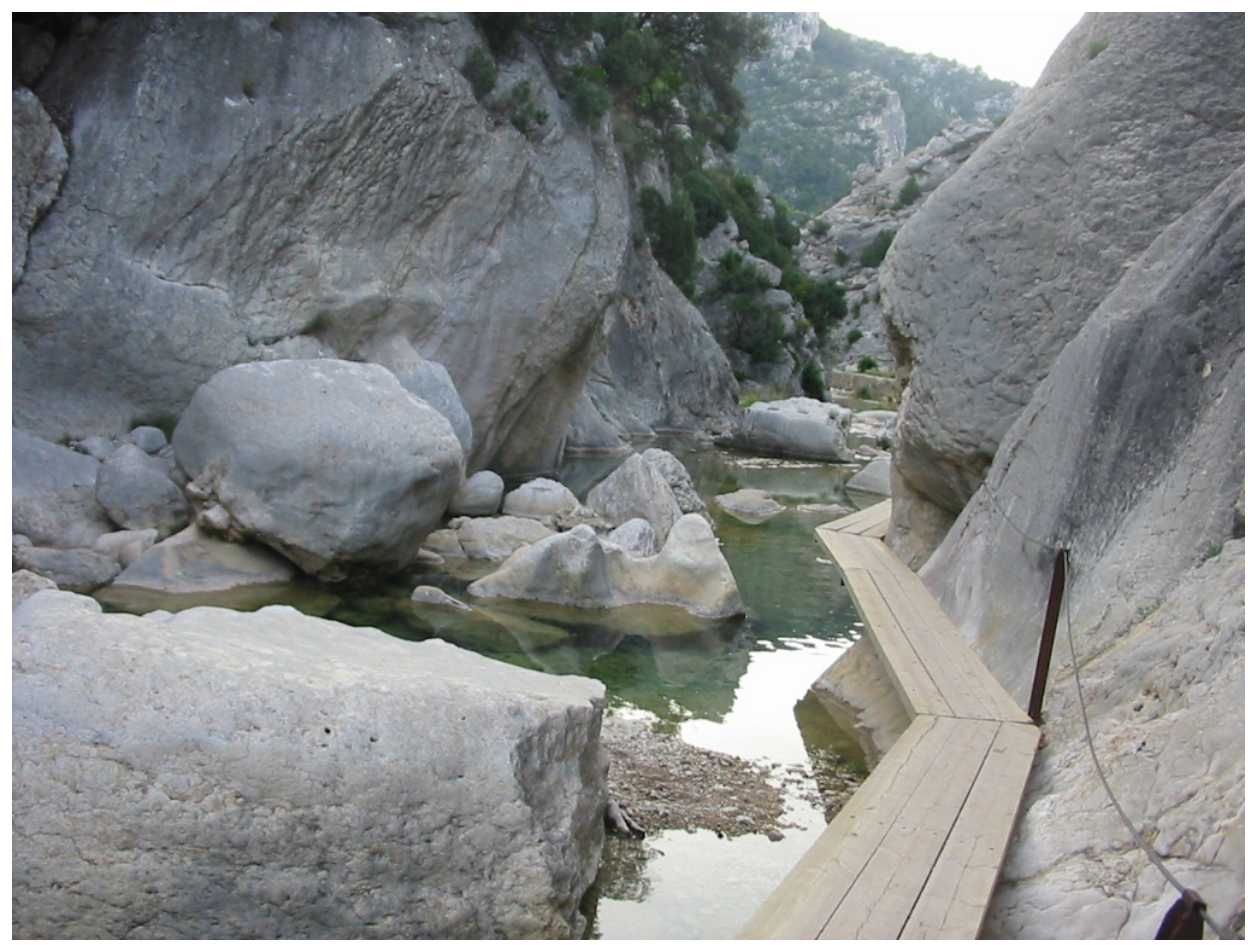

FOTOGRAFIA 8 (PARADA 10)

Els travertins i la travertinització, prop del Parrissal

PARADA 11. ELS GARRIGONS, (terme municipal de Beseit, comarca del Matarranya). (Full 521).

Des de la parada anterior, cal retrocedir fins a la cruïlla amb el camí de Formenta i de Fredes. Així, caldrà passar a l'altra banda del Riu Matarranya per tal de seguir cap al Sud. En arribar al paratge de Tormos es farà una nova aturada, després de recórrer uns 6 Km més, aproximadament. En aquest recorregut s'haurà remuntat sempre el riu Formenta

Aquest recorregut s'haurà efectuat per entre afloraments dels materials mesozoics (del Juràssic i del Cretàcic). Aquests terrenys formen part de la denominada Zona d'Enllaç entre la Serralada Prelitoral Catalana i el Sistema Ibèric.

Molt sovint aquests materials mesozoics queden recoberts per nivells detrítics terciaris que pertanyen a la Formació Montsant, tot i que es troben molt a prop del pas lateral (cap a ponent) al Grup de Mont-roig - Aiguaviva - Alcorisa, de característiques molt semblants. 
Aquests darrers materials es troben en posició discordant amb els anteriors. Prop de Tormos, es veu ben clara una d'aquestes discordances entre els materials secundaris i els terciaris.

Per d'altra banda, en aquest lloc es poden veure els meandres descrits pel riu Formenta (afluent del Matarranya), entre els materials mesozoics carbonatats. FOTOGRAFIA 9.

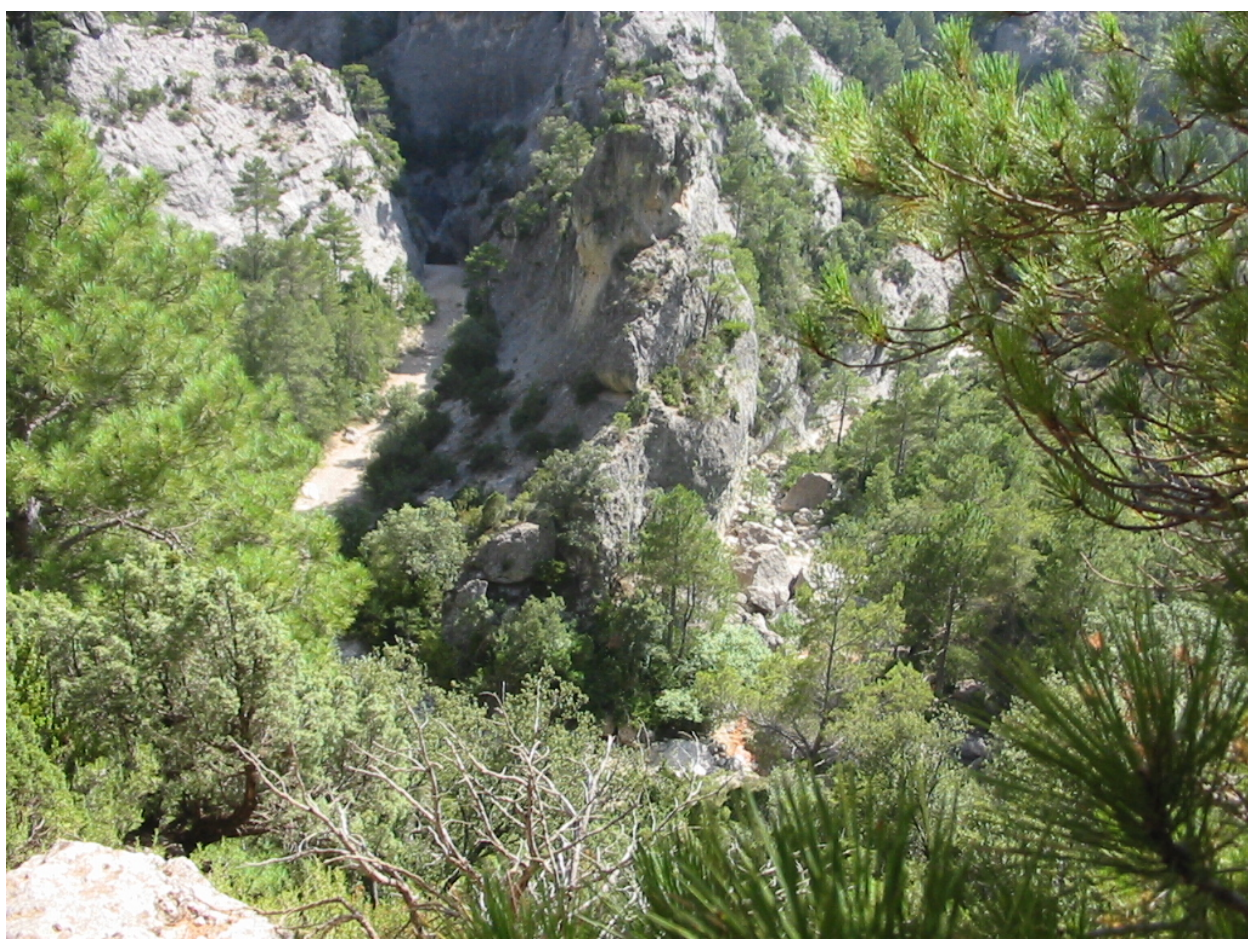

FOTOGRAFIA 9 (PARADA 11)

Els meandres del riu Formenta

PARADA 12. IMMEDIACIONS DE TORMOS, (terme municipal de Beseit, comarca del Matarranya). (Full 521).

Des de la parada anterior, cal seguir pel camí que es dirigeix cap a Formenta. Després d'un recorregut d'uns 2Km, en arribar a les immediacions del Mas del Ganxo, sota de Tormos, caldrà fer una nova aturada.

En aquest recorregut hem anat trobant afloraments dels materials carbonatats mesozoics, els quals pertanyen al Juràssic i al Cretàcic. Els primers són els que hi ha a l'indret de l'aturada. Per d'altra banda, en aquest lloc, just a la vora del camí, després d'una corba s'ha desenvolupat una interessant mineralització ferruginosa associada a 
“hard-ground” amb presencia d'HEMATITES. FOTOGRAFIA 10.

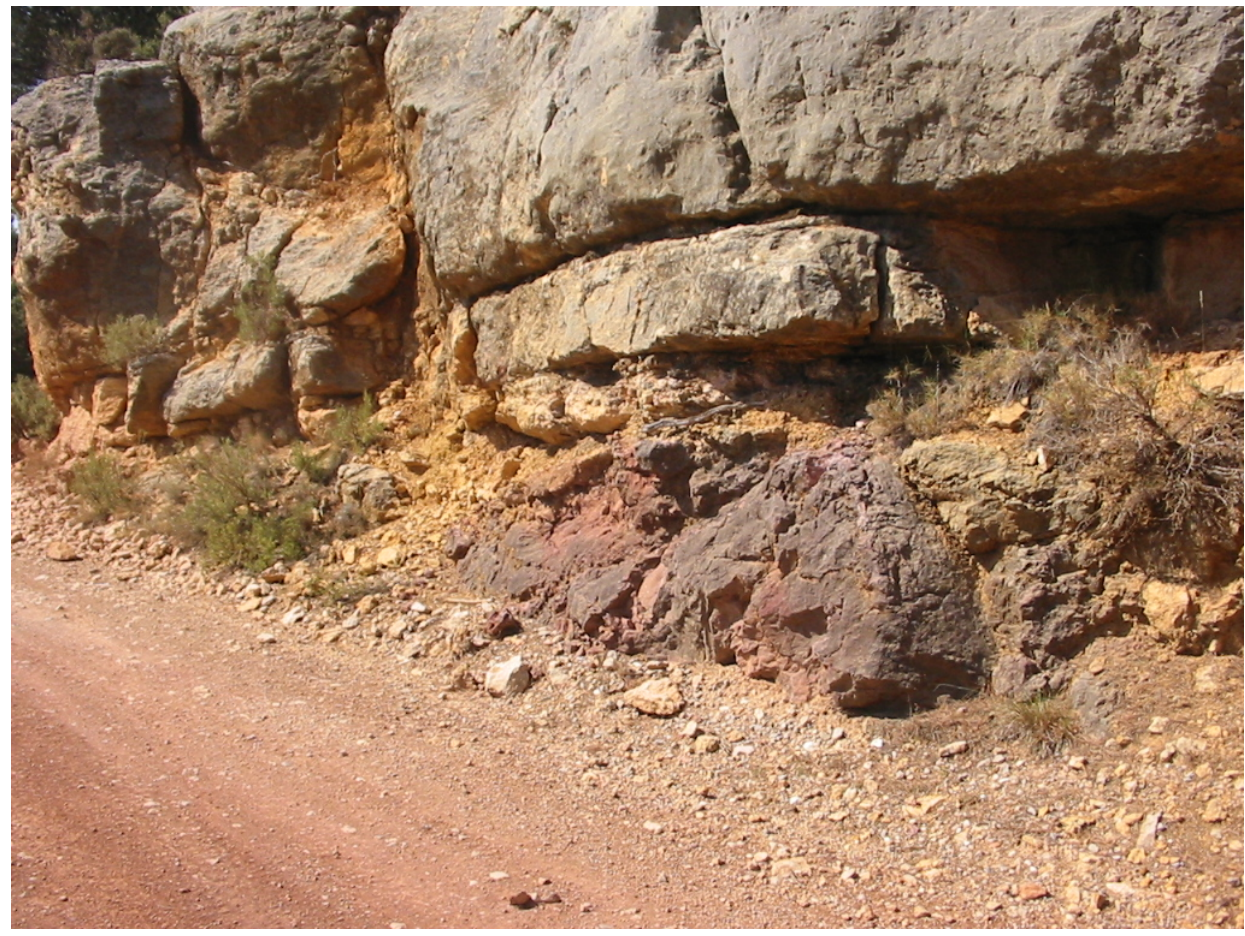

FOTOGRAFIA 10 (PARADA 12)

Hard-ground ferruginós

PARADA 13. MINA D’ARGILA DE FORMENTA, (terme municipal de Beseit, comarca del Matarranya). (Full 521).

Des de la parada anterior, cal seguir pel camí que es dirigeix cap a Formenta. Després d'un recorregut d'uns $3 \mathrm{Km}$, en arribar a les immediacions del Mas de Formenta, caldrà fer una nova aturada, la darrera d'aquest recorregut.

En aquest tram de l'itinerari, haurem continuat trobant afloraments dels materials carbonatats mesozoics, que en bona part pertanyen al Cretàcic Inferior. Més endavant, en arribar a l'indret de l'aturada, haurem començat a trobar afloraments dels nivells terrígens del Cretàcic Mig. Així, haurem arribat als afloraments de l'Albià, amb presència de nivells d'argiles i sorres, que formen part de la Formació Utrillas i també de la Formació Escucha, amb la presencia de lignits.

En aquest indret va haver-hi una antiga explotació dels nivells d'argiles, tot i que el lignit és molt abundant. Es tracta de la Mina de Formenta. Fotografia 11. 


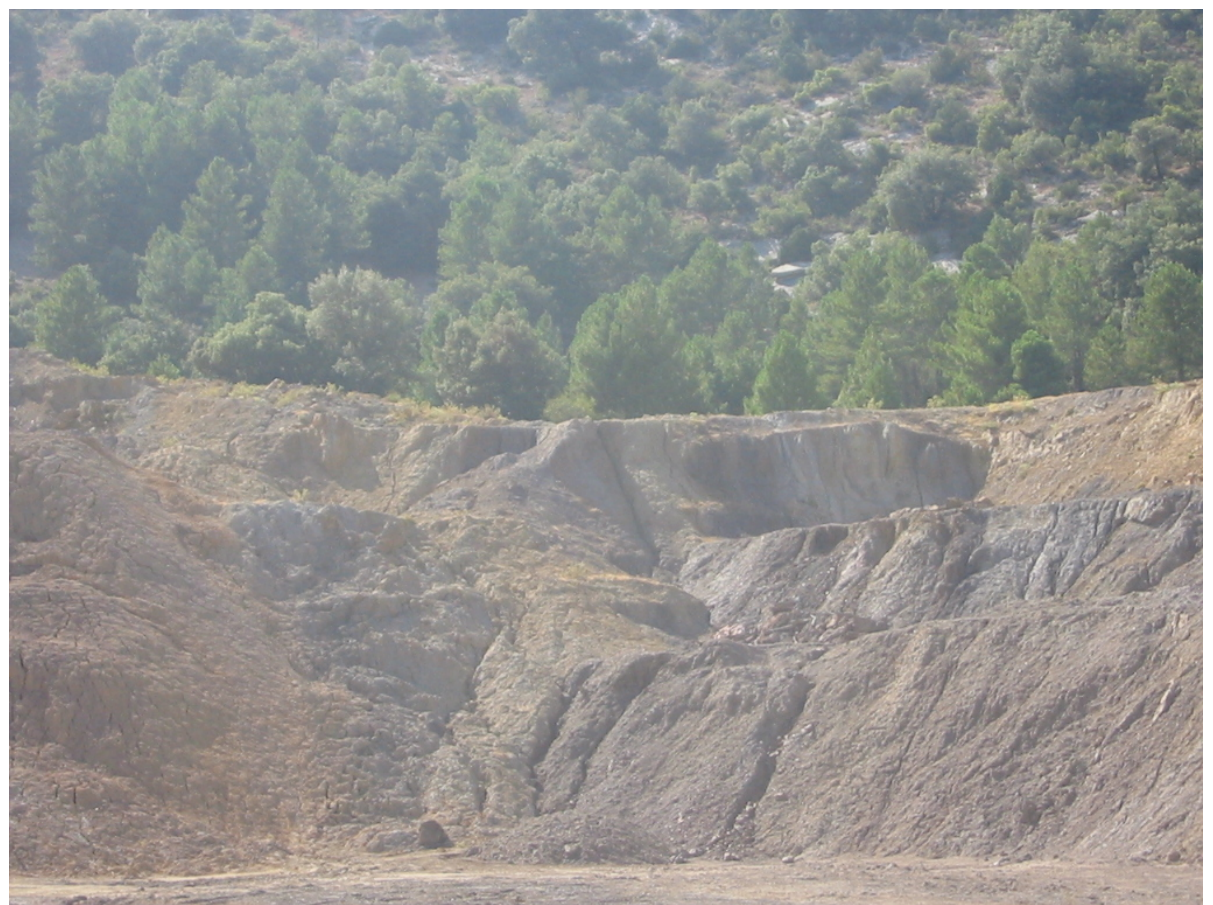

FOTOGRAFIA 11 (PARADA 13)

Un aspecte de les antigues explotacions de la Mina de Formenta

Entre els nivells argilosos, destaca la presència de la CAOLINITA, acompanyada de CALCITAi QUARS. Entre els lignits, hi ha presència de sulfurs de ferro, de caràcter primari. entre ells hi ha la PIRITA, així com la MARCASSITA. Igualment, hi ha indicis de la MELNIKOWITA, un mineral trimorf amb els dos anteriors. Per l'oxidació d'aquests sulfurs acabats d'esmentar, s'ha produït la formació de diversos minerals d'alteració, com de GOETHITA (la qual és sempre molt terrígena, apareixen en forma de la roca LIMONITA). També es troben altres minerals com: GUIX (originat al reaccionar l'àcid sulfúric, procedent de l'alteració dels sulfurs de ferro, amb la CALCITA), i la MELANTERITA.

\section{EN AQUEST INDRET FINALITZA EL RECORREGUT}

\section{REFERÈNCIES BIBLIOGRÀFIQUES}

GUIMERÀ, J. et altri (1992).- Geologia (II), Història Natural dels Països Catalans, Vol.2, 547 pag. Enciclopèdia Catalana, S.A. Barcelona 
IGME (1974).- Mapa Geológico de España a escala 1:200.000. Sintesis de la Cartografia existente. Hoja y memória nº 41 (Tortosa). Inst. Geol. Min. España. Minist. Indústria. Madrid

MATA-PERELLÓ, J.M. (1989).- Una recerca mineralògica per les terres de l’Ebre: del Matarranya al Priorat. But. Col. Ofi, de Doctors i Llicenciats, nº 67, 15pag. Barcelona

MATA-PERELLÓ, J.M. (1991).- Els Minerals de Catalunya. Arxius de la Secció de Ciències, t. XCIII, 442 pag. Institut d'Estudis Catalans. Barcelona

MATA-PERELLÓ, J.M. (1995a).- Inventari Mineralògic de la comarca de la Ribera d’Ebre, Terra Endins, n 9 , 23 pag. Manresa

MATA-PERELLÓ, J.M. (1995b).- Inventari Mineralògic de la comarca de la Terra Alta, Terra Endins, $\mathrm{n}^{\circ}$ 10, 22 pag. Manresa

MATA-PERELLÓ, J.M. (1996).- Itinerari geològic i mineralògic entre Gandesa, la Fontcalda i Vall-de -roures. Inèdit., 12 pàgines. Manresa

MATA-PERELLÓ. J.M. (1997).- Recerca geològica i mineralògica per les comarques de la Terra Alta i del Matarranya: des de Gandesa a Bot i Horta de Sant Joan, i des de Vallde-roures a Fondespatlla. Inèdit, 17 pàg. Manresa

MATA-PERELLÓ. J.M. (2000a).- Recerca geològica i mineralògica per les comarques de la Terra Alta i de la Ribera de l'Ebre: des de Pinell de Brai i Prat de Compte a Gandesa i a Mora d’Ebre. Algeps, sèrie B, nº 171, 14 pàg. Manresa

MATA-PERELLÓ. J.M. (2000b).- Recerca geològica i mineralògica per les comarques de la Terra Alta i del Matarranya: des de Gandesa a Vall-de-roures i a Fondespatlla. Algeps, sèrie $B, n^{\circ} 176,18$ pàg. Manresa

MATA-PERELLÓ. J.M. (2001a).- Recorregut de recerca geològica i mineralògica per les comarques de la Ribera d'Ebre i de la Terra Alta: des d'Ascó a Pinell de Brai, i des de Prat de Compte a Horta de Sant Joan, Inèdit, 18 pàg. Manresa

MATA-PERELLÓ. J.M. (2001b).- Recorregut de recerca geològica i mineralògica per les comarques de la Terra Alta i del Matarranya: des d'Horta de Sant Joan a Vall-de-roures i a Fontespatlla Inèdit, 18 pàg. Manresa

MATA-PERELLÓ. J.M. (2005a).- Recorreguts per la comarca de la Terra Alta: des de Pinell de Brai a Prat de Compte i a Horta de Sant Joan. Inèdit. 12 pàgines. Manresa

MATA-PERELLÓ. J.M. (2005b).- Recorreguts de recerca geològica i mineralògica per les comarques de la Terra Alta i del Matarranya: des d'Arnes a Vall-de-roures i Beseit. Inèdit. 10 pàgines. Manresa

Rodenol.2015 n.3 | Recorregut de recerca geològica i mineralògica per les comarques de la terra alta i del Matarranya: des d'Horta de Sant Joan i Arnes a Vall-de-Roures i a Beseit; i des de Beseit al Parrissal i a 
MATA-PERELLÓ. J.M. (2011).- Recorregut de recerca geològica i mineralògica per les comarques de la Terra Alta i del Matarranya: des d'Horta de Sant Joan i Arnes a Vall-deRoures i a Beseit. Inèdit. 14 pàgines. Manresa

RIBA, O. et altri (1976).- Geografia Física dels Països Catalans, Edit. Ketres, 254 pàgines. Barcelona. 


\section{Apartat}

Text de l'article. Sense indexació i amb separaciò entre paràgrafs2.

\subsection{Subapartat}

Text de l'article. Sense indexació i amb separaciò entre paràgrafs.

2 Ejemplo de nota. Con estilo nota al pie.fjdf jfj fjd sdlkfj sdjfjfkj flljkdf sddfjdflj dfjsdlfj ñfljdk Ifdjljldjf Idfj añsljdnf dñjdf 
RODENO. Revista de geología aragonesa

Rodenol.2015 n.3 | Recorregut de recerca geològica i mineralògica per les comarques de la terra alta i del 